\title{
Organic brain syndrome with psychosis as an initial manifestation of systemic lupus erythematosus in an elderly woman
}

\author{
M E Mavrikakis, L G Antoniades, J B Germanides, D Sotou, A Rassidakis
}

\begin{abstract}
This paper describes a rare case of organic brain syndrome with psychosis and clinically transverse myelopathy, as initial manifestations of systemic lupus erythematosus in an elderly woman. The identification and evaluation of antibodies to ribosome $P$ in the serum and cerebrospinal fluid may be of help in such cases for differential diagnosis. The patient was treated successfully with $30 \mathrm{mg}$ prednisone daily.
\end{abstract}

Systemic lupus erythematosus (SLE) attacks the central nervous system (CNS) in a way that can lead to a wide spectrum of clinical manifestations. ${ }^{1}$ The neurological manifestations of SLE are usually seen in combination with other clinical features and are rarely the primary sign of the disease. ${ }^{2}$

In the elderly the clinical picture usually follows the pattern: serositis, arthritis, arthralgia, myalgia; while renal disease hypocomplementaemia, neuropsychiatric disturbances, alopecia, and Raynaud's phenomenon are uncommon. ${ }^{34}$

We describe a rare case of SLE in an elderly woman, in which the primary manifestation was organic brain syndrome with psychosis and clinically transverse myelopathy. This case highlights the difficulty in differential diagnosis between SLE and other diseases with a similar clinical picture, emphasises the diagnostic value of antibodies to ribosome $\mathrm{P}$, and provides an example of successful clinical management of CNS-SLE with relatively small doses of steroids. It is reported that moderate doses, as low as 30 mg prednisone daily, may be quite effective in some patients. ${ }^{5}$

\section{Case report}

A woman aged 78 years was admitted to the clinic with the following symptomatology, according to information provided by her family: for six months, numbness in the extremities, with increasing pain and difficulty in walking; for four months, loss of bowel and bladder sphincter control, and mental disturbances; for two months, temperature fluctuations of the order of 37.3 to $38^{\circ} \mathrm{C}$, drowsiness, memory disturbances, loss of orientation, with occasional agitation and delirium. There was nothing unusual in the patient's personal history or habits. of consciousness, with responsiveness to intense painful stimulation, a medium ability to communicate, and an inability to stand without assistance. Sensory examination was impossible. Tendon jerk reflexes of the upper extremities were normal but those of the lower extremities were absent on the right and depressed on the left; plantar reflexes were both indifferent. There was a loss of bowel and bladder sphincter control. These later clinical findings are compatible with transverse myelopathy at a low level. Other findings were unremarkable.

\section{PSYCHIATRIC EXAMINATION}

Psychiatric examination showed that the delirium was not due to alcohol or drug abuse. She showed impaired recent memory and disturbed orientation, impaired level of consciousness, and psychomotor nervousness alternating with apathy. The sleep-wakefulness cycle was disturbed with predominant insomnia. She misrecognised faces and had delusions, emotional disturbances, and anxiety and nervousness alternating with apathy.

\section{PHYSICAL EXAMINATION}

Physical examination showed a severely ill overweight patient. Skin, conjunctiva, and mucous membranes were pale. Lungs, heart, and alimentary tract were normal.

\section{LABORATORY FINDINGS}

Laboratory findings were as follows: haemoglobin $90 \mathrm{~g} / 1$, packed cell volume $0 \cdot 293$, red blood cell count $3 \cdot 14 \times 10^{12} / 1$, white blood cell count $3 \times 10^{9} / 1$ with normal differential, platelets $253 \times 10^{9} / 1$, erythrocyte sedimentation rate $90 \mathrm{~mm} / \mathrm{lst} \mathrm{h}$ (Westergren). Haemoglobin and cellular casts were obtained from the urine. A 24 hour urine sample showed only traces of protein.

Serum potassium, sodium, calcium, phosphorus, urea nitrogen, creatinine, glucose, aspartate transaminase, alanine transaminase, lactic dehydrogenase, creatine kinase, $\gamma$ glutamyltransferase, alkaline phosphatase, uric acid, iron, vitamin B-12, folate, CEA, $\alpha$ fetoprotein, triiodothyronine, thyroxine, thyroid stimulating hormone, and ammonia were all within normal limits. Prothrombin time was $100 \%$. Total serum protein was $58 \mathrm{~g} / 1$. Protein electrophoresis gave $\mathrm{Al} \mathbf{4 4} \cdot 7 \%, \alpha_{1} \mathbf{6} \cdot 7 \%, \alpha_{2}=$ $13 \cdot 8 \%, \beta 14 \cdot 3 \%, \gamma 20 \cdot 1 \%$. Widal's test, Wright's test, monotest, blood cultures, and urine cultures were all negative. $C$ reactive protein was not present; $\mathrm{Ra}$ test, latex, and LE cell tests 
were negative; anti-DNA was $10.6 \mathrm{mg} / \mathrm{l}$ (normal <5), C3 1.36 g/l (normal 0.7-1·76), C4 $175 \mathrm{mg} / \mathrm{l}$ (normal 160-500); antinuclear antibodies, antiSSA/SSB, anti-Sm/RNP, anti-Scl70 were not present; antibodies to ribosome $P$ were present $(+++)$; Coombs' test was negative, serum circulating immune complexes were $42 \cdot 7 \mathrm{mmol} / \mathrm{l}$ (normal <20), IgG $9.8 \mathrm{~g} / 1, \operatorname{IgA} 4.8 \mathrm{~g} / \mathrm{l}, \mathrm{Ig} M$ $2 \cdot 7 \mathrm{~g} / \mathrm{l}$.

The cerebrospinal fluid showed normal general features and the following values were obtained: $\mathrm{pH} 7 \cdot 0$, glucose $1 \cdot 7 \mathrm{mmol} / 1$, protein $290 \mathrm{mg} / \mathrm{l}$, red blood cells $1.05 \times 10^{9} / 1$, white blood cells $10^{7} / 1$, C3 $30 \mathrm{mg} / \mathrm{l}, \mathrm{C} 450 \mathrm{mg} / \mathrm{l}$, antiDNA $9.3 \mathrm{mg} / \mathrm{l}$, antibodies to ribosome $P$ strongly positive $(+++)$, culture negative, Koch's bacillus test negative.

Brain computed tomography showed ventricular dilatation indicative of cerebral atrophy greater than expected for the patient's age. Magnetic resonance imaging showed cerebral atrophy. An ocular examination gave negative results. Results of a skin biopsy were compatible with collagen disease.

Her family refused to allow further investigations and so examination of the spinal cord by computed tomography and magnetic resonance imaging were not carried out.

\section{Discussion}

Organic brain syndrome may be due to a wide variety of conditions ${ }^{6}$ - for example, infections such as meningitis or intracerebral abscess; metabolic illnesses such as uraemia or hepatic failure with hyperammonaemia; disturbances of electrolyte balance such as hypo- or hypernatraemia, hypo- or hyperkalaemia; severe hypoxaemia; overuse of drugs such as atropine or anticonvulsants, or withdrawal from barbiturates or alcohol; space occupied lesions such as neoplasms, haematoma, or even multiple cerebral arterial emboli; endocrine diseases, mainly hyper- or hypothyroidism; cerebral atrophy. These were ruled out, firstly, by the clinical history, which contained no reference to drug abuse, and, secondly, by the findings of the biochemical blood tests for metabolic disturbances and endocrine diseases, by the findings from the cerebrospinal fluid concerning infections, and by the methods used to visualise the brain, which eliminated the possibility of space occupied lesions or vascular damage.

In such cases, where the main causes of organic brain syndrome, with or without psychosis, have been ruled out, one must look for other rare diseases to which the syndrome might be attributable, such as SLE. In this particular patient the organic brain syndrome with psychosis, after exclusion of other possible causes, was strongly suggestive of SLE, as the proposed criteria of the American Rheumatism Association for the diagnosis of $\mathrm{SLE}^{7}$ were satisfied-namely, (a) haematological-leucopenia, absolute lymphopenia; $(b)$ immunological -antibodies to ribosome $\mathrm{P}(+++)$, antiDNA ( + ). In the cerebrospinal fluid, antibodies to ribosome $\mathbf{P}(+++)$, low concentrations of C3, C4; $(c)$ neuropsychiatric manifestations; $(d)$ renal disease-persistent haematuria, cellular casts.
Organic brain syndrome is the most common severe manifestation of CNS-SLE and is characterised by the abrupt or gradual onset of memory impairment, loss of orientation, intellect, or judgment, apathy, irritability, or delirium. The symptoms may either be transient and fluctuate with the activity of the disease or there may be a slow but progressive deterioration. $^{1}$

Psychosis occurs in 10-50\% of patients with SLE ${ }^{8}$ and usually coexists with organic brain syndrome. Clinically, psychosis may appear in (a) severely systemically ill patients; (b) patients with a milder clinical course, but in combination with other neurological signs; $(c)$ patients with or without other clinical indications and with or without other abnormal serological tests for SLE. ${ }^{1}$ Our patient falls into this last category.

The positive antibodies to ribosome $P$ in the serum and cerebrospinal fluid have particular diagnostic value as they may serve as an additional serological index for the diagnosis of SLE, given that they may be detected in the serum even when there are no other positive immunological indices, such as anti-dsDNA (35\% of patients with SLE with antibodies to ribosome $\mathbf{P}$ did not have anti-dsDNA ${ }^{9}$ ). The recent identification of antibodies to ribosome $P$ in the serum and cerebrospinal fluid of patients with SLE emphasises the high correlation between psychosis resulting from SLE and these antibodies. Bonfa et al noted that 18 of 20 patients with psychosis arising from SLE had antibodies to ribosome $P$, whereas there was no such finding either in patients with SLE and other CNS manifestations, patients with SLE and intermittent behaviour abnormalities due to steroids, patients with psychosis but without SLE, or in normal subjects. ${ }^{10}$ Similar findings were reported by Golombek et al. ${ }^{11}$ The mechanism through which the antibodies to ribosome $\mathrm{P}$ are responsible for psychotic manifestations of SLE is believed to be via the bloodbrain barrier, ${ }^{12}$ so that cytotoxins act by affecting the neurotransmitters or neurones.

Other laboratory findings supporting the diagnosis of SLE of the CNS were the low concentrations of cerebrospinal fluid complement ${ }^{13}$ and the degree of cerebral atrophy shown by the cerebral computed tomography and magnetic resonance imaging examinations, which was greater than expected for the patient's age. ${ }^{14}$

The diagnosis of transverse myelopathy in our patient was based on the typical clinical findings and supported by the low cerebrospinal fluid glucose concentration. ${ }^{1}$ It is a rare complication of CNS-SLE, like other rarely reported complications such as diabetes insipidus. ${ }^{15}$

Treatment of SLE in the elderly is subject to the same problems as treatment of the young, though the average corticosteroid needed may be less in the elderly. ${ }^{16} 17$ The favourable response of the patient to relatively low doses of steroids (30 mg prednisone daily) is worth noting. A clear clinical improvement was seen within five days, particularly in the patient's mental state, but the clinical signs of transverse myelopathy did not improve to the same extent.

In conclusion, it is suggested that in cases of 
organic brain syndrome with psychosis in the elderly, doctors should consider the possibility of SLE with associated CNS abnormality; the presence of antibodies to ribosome $P$ should be checked for and, if present, the condition should be treated with moderate doses of steroids.

1 McCune W J, Colbus J. Neuropsychiatric lupus. Rheum Dis Clin North Am 1988; 14: 149-67.

2 Barry B. CNS lupus. Clin Rheum Dis 1982; 8: 183-95.

3 Ballou S P, Khan M A, Kuchner I. Clinical features of systemic lupus erythematosus: differences related to race and age of onset. Arthritis Rheum 1982; 25: 55-60.

4 Wilson H A, Hamilton M E, Spyker D A, et al. Age influences the clinical and serologic expression of systemic lupus erythematosus. Arthritis Rheum 1981; 24: 1230-5.

5 Steinberg D A. Management of systemic lupus erythematosus. In: Kelley W N, Harris E D, Ruddy S, Sledge C B, eds. Textbook of rheumatology. 2nd ed. Philadelphia: Saunders, 1985; 1098-115.

6 Sherman D G. Disorders of intellect. In: Stein J H, ed. Internal Medicine. 2nd ed. Boston, Toronto: Little, Brown, 1987: $2150-3$.

7 Tan E M, Cohen A S, Fries J F, et al. The 1982 revised criteria for the classification of systemic lupus erythematosus. Arthritis Rheum 1982; 25: 1271-7.
8 Hall R C, Stickney S K, Gardner E R. Psychiatric symptoms in patients with systemic lupus erythematosus. Psychosomatics $1981 ; 22$ : 15-24.

9 Bonfa E, Elkon K B. Clinical and serologic associations of the anti-ribosomal P protein antibody. Arthritis Rheum 1986; 29: 981-5.

10 Bonfa E, Golombek S J, Kaufman L D, et al. Association between lupus psychosis and anti-ribosomal $\mathbf{P}$ protein antibodies. $N$ Engl F Med 1987; 317: 265-71.

11 Golombek S J, Graus F, Elkon K B. Autoantibodies in the cerebrospinal fluid of patients with systemic lupus erythematosus. Arthritis Rheum 1986; 29: 1090-7.

12 Zvaifler $\mathrm{N} \mathrm{J}$, Bluestein $\mathrm{H} \mathrm{G}$. The pathogenesis of central nervous system manifestations of systemic lupus erythenervous system manifestations of systemic
matosus. Arthritis Rheum 1982; 25: 862-6.

13 Rothfield N F. Systemic lupus erythematosus: clinical aspects and treatment. In: McCarty D J, ed. Arthritis and allied conditions. 11th ed. Philadelphia: Lea and Febiger, 1989: 1022-48.

14 Kaell A T, Shetty M, Lee B C, Lockshin M D. The diversity of neurologic events in systemic lupus erythematosus. Prospective clinical and computed tomographic classification of 82 events in 71 patients. Arch Neurol 1986; 43: 273-6.

15 Mavrikakis M, Papadoyannakis N, Kotsakis P, Hartzoulakis I, Moulopoulos S. Systemic lupus erythematosus: two cases with unusual clinical presentation. Rheumatology 1980; 10: 413-7.

16 Stevens B M. Connective tissue disease in the elderly. Clin Rheum Dis 1986; 12: 11-32.

17 Baker S B, Rovira J R, Campion E W, Mills J A. Late onset systemic lupus erythematosus. Am $\mathcal{F}$ Med 1979; 66: 727-32. 